\title{
The Jablonna conference on gravitation: a continuing source of inspiration
}

\author{
Marek Demianski
}

Received: 21 January 2014 / Accepted: 11 March 2014 / Published online: 23 May 2014

(C) The Author(s) 2014. This article is published with open access at Springerlink.com

First of all I would like to welcome all of you at the main campus of the University of Warsaw-my University. Especially warmly I would like to welcome the youngest participants who for the first time participate in a big international conference. I do understand how you feel, I do understand your anxiety. Fifty one years ago I was able to observe the International Jablonna Conference on General Relativity and Gravitation, that later was classified as the GRG-3 conference. In June of 1962, I got my Master of Science degree in physics. My thesis advisor, Professor Leopold Infeld, was the Chairman of the Local Organizing Committee of the Jablonna conference. Professor Infeld asked me to help with such simple tasks as cleaning the blackboard, make sure that chalk was always available, but also - and this was really important-every morning to collect participants who were staying in hotels in Warsaw into a special coach and bring them in time to Jablonna, and in the evening bring them back to Warsaw. So that is how I ended up listening to all lectures and discussions and more. Now looking back from the perspective of half a century I think that the Jablonna Conference was the most important scientific conference that I attended so far.

The opening session of the Jablonna conference was held at the Staszica Palace in Warsaw, a short walk from where we are now. It is an easy recognizable building, in front of it is the famous monument of Copernicus (Fig. 1). The first talk was delivered by Professor J. L. Synge on "Relativistic interpretation and modification of Newtonian models". On Fig. 2 is Professor J. Synge delivering his talk and, in the first row (from the left) Professors L. Infeld, V. Fock, J. Anderson, T. Newman, R. Penrose and B. Hoffman, and on the far right Dr. Róża Michalska-Trautman. After the first talk,

This article belongs to the Topical Collection: The First Century of General Relativity: GR20/Amaldi10.

M. Demianski ( ()

Institute of Theoretical Physics, Hoza 69, 00-681 Warsaw, Poland

e-mail: marek.demianski@fuw.edu.pl 


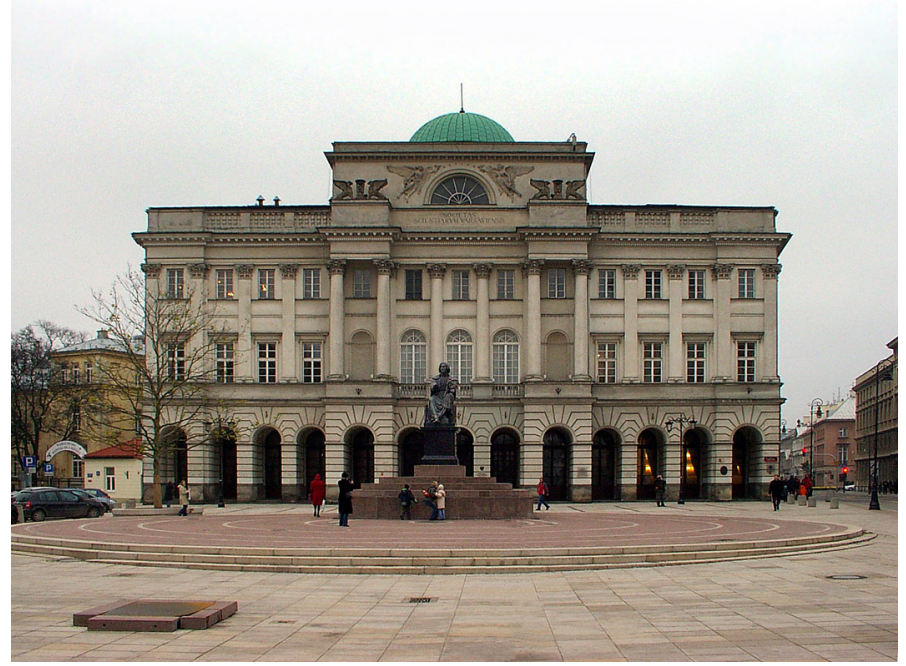

Fig. 1 The Staszica Palace in Warsaw

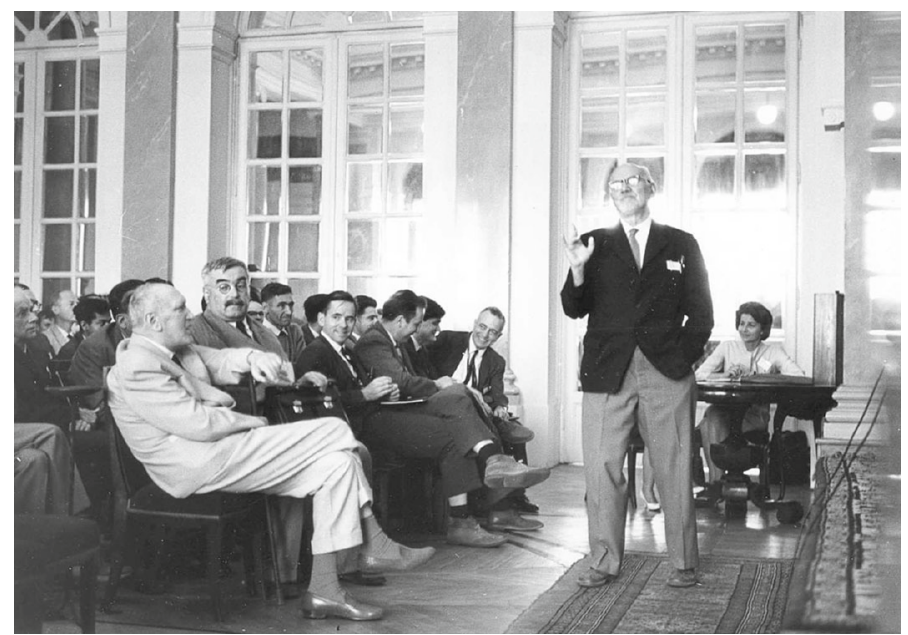

Fig. 2 Professor J. Synge delivering the opening lecture

followed by a short discussion, the session was adjourned and all participants were transferred to Jablonna.

Jablonna is a small town about $20 \mathrm{~km}$ from Warsaw. In XVIII century a famous Polish aristocratic family of Poniatowski built there a summer palace and two adjacent buildings with several rooms for their guests and servants. The Palace was surrounded by a park of English style (Fig. 3).

The idea to organize cyclic international conferences on general relativity and gravitation slowly matured over the years after the Second World War. In 1955, to celebrate the fiftieth anniversary of the special theory of relativity, an international conference 
was organized in Bern (Switzerland). Albert Einstein's death in April 1955 affected the atmosphere at that conference. In spite of this, 89 renown scientists participated in this meeting; among them there were four Nobel Prize winners ( M. Born, M. von Laue, W. Pauli, and E. Wigner). The political division of the world after the second World War was clearly noticeable in the disparity in the number of participants form the West (85) and the East (3, including 2 from the USSR). At the Bern conference, special relativity was hardly mentioned and the main topics of discussions concentrated on quantization of gravity, gravitational radiation, equations of motion and cosmology. At Bern it was decided to organize in 1957 another conference devoted to general relativity and its role in physics. The first international GRG conference was organized in 1957 at Chapel Hill (North Carolina, USA). Only 46 scientists participated in that meeting. There was not a single person from the East. It was decided there to organize a consecutive conference in 1959 in France. The Royaumont meeting was attended by 119 scientists including 8 from the East ( 3 from the USSR). At Royaumont it was decided that the next GRG conference should be held in Poland and Professor Leopold Infeld became the chairman of the Local Organizing Committee. Without Professor Infeld's status and influence it would not have been possible to organize the Jablonna conference (Fig. 4).

Leopold Infeld born in Cracow in 1898 was educated in Poland. He studied physics at the Jagiellonian University where in 1921 he obtained the $\mathrm{PhD}$ degree. Later, for several years, he was a high school teacher in Konin. For 3 years (1930-1933) he worked as an assistant and a private docent at the University of Lwów. Since Infeld was Jewish, there was very little chance for him to obtain a permanent position in Poland. In 1933 Infeld went to England, where he collaborated with Max Born: this led to the formulation of the Born-Infeld electrodynamics. In 1936 Leopold Infeld obtained a fellowship at the Institute for Advanced Study and worked with Albert

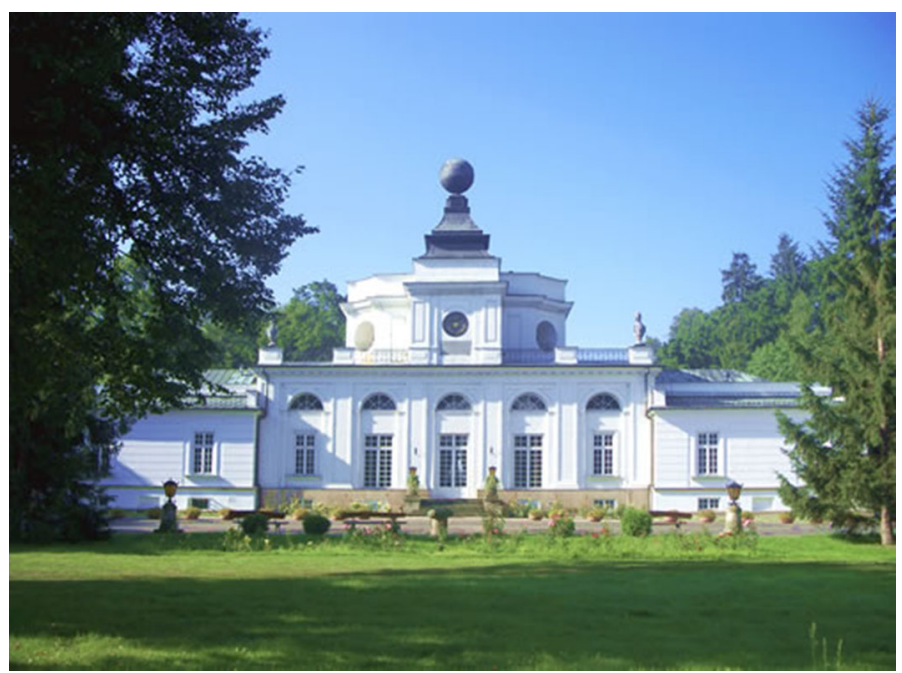

Fig. 3 The Palace in Jablonna 
Fig. 4 Albert Einstein with

Peter Bergmann (left) and

Leopold Infeld (right)
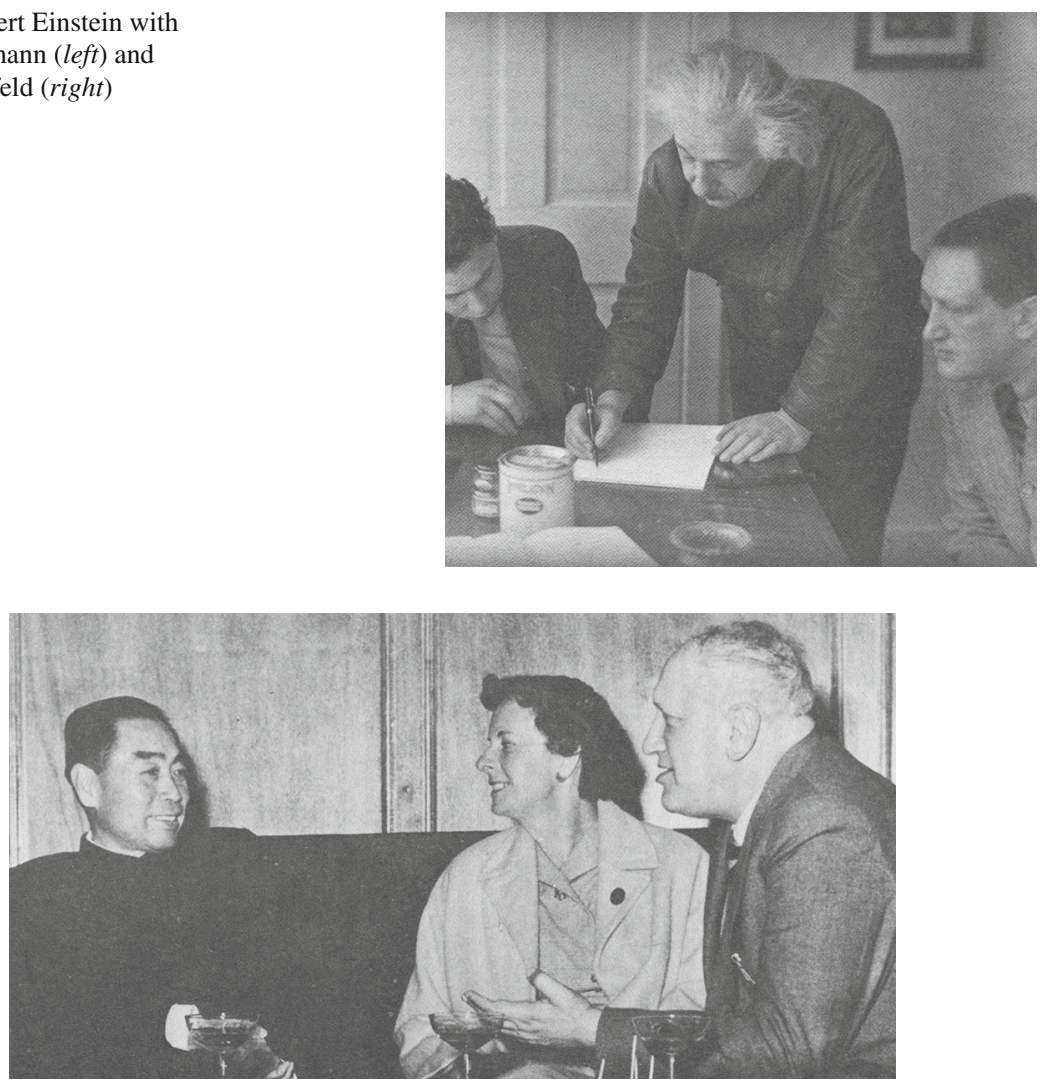

Fig. 5 Leopold Infeld and his wife Helen chatting with Chou En Lai

Einstein in Princeton. In collaboration with Banesh Hoffman they formulated a new method of deriving equations of motion of compact sources of gravitational field from Einstein's field equations, now known as the EIH method. During his stay at Princeton, Infeld persuaded Einstein to jointly write a popular book on physics, The Evolution of Physics. This book became a bestseller and has been translated into many languages. For eleven years (1939-1950) Infeld was a professor of physics at the University of Toronto (Canada). In 1950 Infeld decided to return back to Poland and settled in Warsaw where in collaboration with another returning Polish physicist Wojciech Rubinowicz they organized the Institute of Theoretical Physics at the University of Warsaw. Infeld was very active in the international movement of leftist intellectualsthe Pugwash Movement on Science and World Affairs-and was a member of the Pugwash Continuing Committee and Soviet dominated World Peace Movement. Figure 5 shows Leopold Infeld and his wife Helen chatting with Chou En Lai, then the Prime Minister of China, during Infeld's visit to China in 1958.

The Jablonna conference was very important for several reasons. Geographic location and Infeld's strive to attract participants from the East brought to Jablonna 114 participants including 33 from the East (11 from the USSR). For the first time since 
Fig. 6 Paul Dirac and Richard Feynman at Jablonna

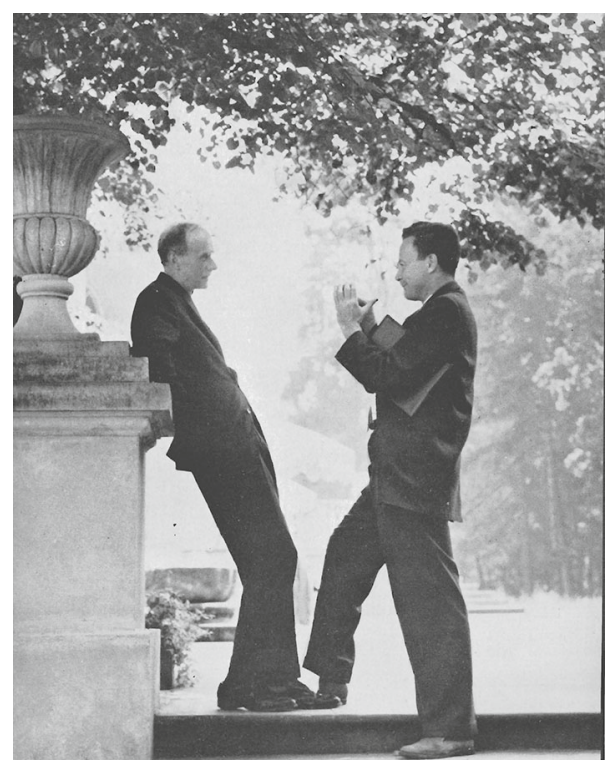

the 2nd World War such a large group of physicists from the West and the East were able to meet. There were continuous discussions, usually in small groups between scientists coming from the West and the East. Also Germans from the DDR and the Bundes Republik were able to meet for the first time since the construction of the Berlin wall. It was a conference attended by many outstanding scientists. All leading physicists working at that time on general relativity and gravitation were present in Jablonna, including P. A. M. Dirac, R. Feynman, J. A. Wheeler, P. G. Bergmann, H. Bondi, S. Chandrasekhar, B. DeWitt, V. Ginzburg, D. Ivanenko, A. Lichnerowicz, C. Moller, L. Rosenfeld and J. Weber among others. One can say that Jablonna was a nesting place of Nobel Prize winners-Paul Dirac, Richard Feynman, Subrahmanyan Chandrasekhar, Vitali Ginzburg and also Peter Higgs were there. The main topics of discussions in Jablonna concentrated on general properties of gravitational radiation, quantization of gravity and exact solutions of the Einstein field equations. Only one talk given by Vitali Ginzburg was devoted to observational tests of general relativity (Figs. 6, 7, 8).

The most memorable lecture, in a dynamic showman style, was delivered by Richard Feynman. He presented his program of quantizing general relativity modeled on his very successful approach to quantum electrodynamics. Of course, he used Feynman diagrams. I am sure that Abhay Ashtekar will tell you more about it. After the conference I have listened to Feynman's talk many times trying to transcribe it from tapes. Fortunately John Stachel stayed in Warsaw for several months after the conference and he was able to unravel the most difficult parts. The printed version (Acta Physica Polonica (1963), XXIV, 697) is an interesting reading even now. As you can guess, the discussion after Feynman's talk was very lively and long. Let me quote two passages that illustrate Feynman's style and the atmosphere after the talk. 


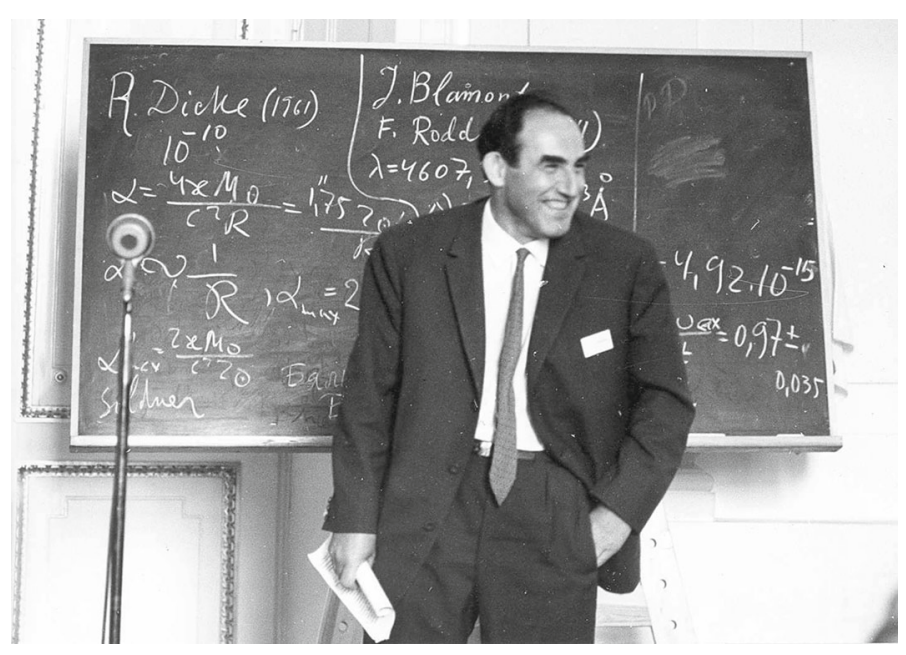

Fig. 7 Vitali Ginzburg delivering his lecture at the Jablonna conference

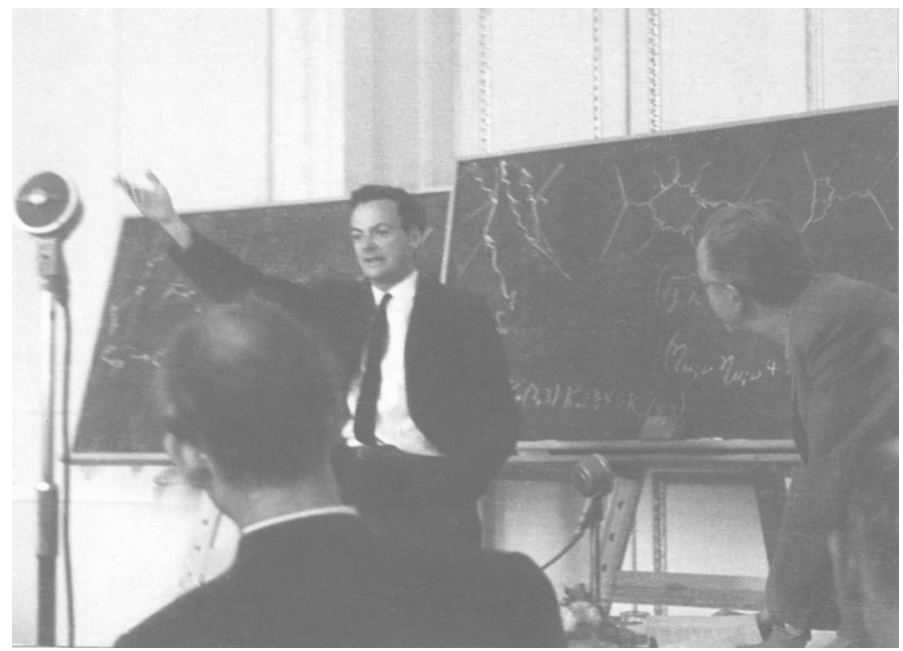

Fig. 8 Richard Feynman delivering his lecture at the Jablonna conference

"Incidentally, to give you some idea of the difference in order to calculate this diagram Fig. $4 \mathrm{~b}$ the Young-Mills case took me about a day; to calculate the diagram in the case of gravitation I tried again and again and was never able to do it; and it was finally put on a computing machine-I don't mean the arithmetic, I mean the algebra of all the terms coming in, just the algebra; I did the integrals myself later, but the algebra of the thing was done on a machine by John Matthews so I couldn't done it by hand. In fact, I think it's historically interesting that it's the first problem in algebra that I know of that was done on a machine that has not been done by hand." Just for the record-already in 1962 to do complicated symbolic calculations Feynman used 
computers, keep in mind that at that time nobody heard about Mathematica or Maple and LISP was known to only a few experts.

"DeWitt: Because of the interest of the tricky extra particle that you mentioned at the end, and its possible connection, perhaps, with some work of Dr Białynicki-Birula, have you got far enough on that so that you could repeat it with just a little more detail? The structure of it and what sort of an equation it satisfies, and what is its propagator? These are technical points, but they have an interest.

Feynman: Give me ten minutes. And let me show how the analysis of these tree diagrams, loop diagrams and all this other stuff is done mathematical way. Now I will show you that I too can write equations that nobody can understand. Before I do that I should like to say that there are a few properties that this result has that are interesting. First of all in the Yang-Mills case there also exists a theory which violates the original idea of symmetry of the isotopic spin (from which was originally invented) by the simple assumption that the particle has a mass. That means to add to the Lagrangian a term $-m^{2} a_{\mu} a^{\mu}$ where $a_{\mu}$ is an isotropic vector. You add this to the Lagrangian. This destroys the gauge invariance of the theory-it's just like electrodynamics with a mass, it's no longer gauge-invariant, it's just a dirty theory. Knowing that there is no such field with zero mass people say: "let's put the mass term on". Now when you put a mass term on it is no longer gauge invariant. But then it is also no longer singular. The Lagrangian is no longer singular for the same reason that it is not invariant. And therefore everything can be solved precisely."

During the conference Feynman has spent a lot of time talking with many people also with young participants. I was fortunate to have several conversations with Feynman in Jablonna and later when I have spent a semester at Caltech in 1974 he recognized me and invited me to participate in many very interesting discussions not only on physics.

At the Jablonna conference I witnessed the process of technology transfer from the West to the East. This might be of interest to participants of the Amaldi 10 conference. In Jablonna, Feynman pressed Joseph Weber to explain how he intends to detect gravitational waves.

Reluctantly Weber gave a short seminar talk and on the blackboard he very schematically drew his famous bar antenna. Later that day Dmitri Ivanenko took Joseph Weber to a remote part of meadows surrounding the Jablonna Palace and tried to wring from him as much information on his antenna as possible. After returning back to Moscow, Ivanenko persuaded Braginsky to start developing similar gravitational wave antenna. That was the beginning of the Moscow group working on gravitational wave detectors. Braginsky and several other members of his group now actively participate in the LIGO collaboration (Figs. 9, 10).

At the Jablonna conference I met several young scientists from the West. I remember long walks along the banks of the Vistula river with Ray Sachs discussing not only physics but also life in the USA and in Poland. Ray had been discharged from the US army several months before coming to Jablonna and I had just finished my military training in Warsaw, so there was a lot to talk about and also to compare military jokes. Ted Newman introduced me to the Newman-Penrose formalism that I later used to find new solutions of the Einstein field equations. I remember how I was captured by Roger Penrose's description of the compactified Minkowski space and the notion of the scri. 


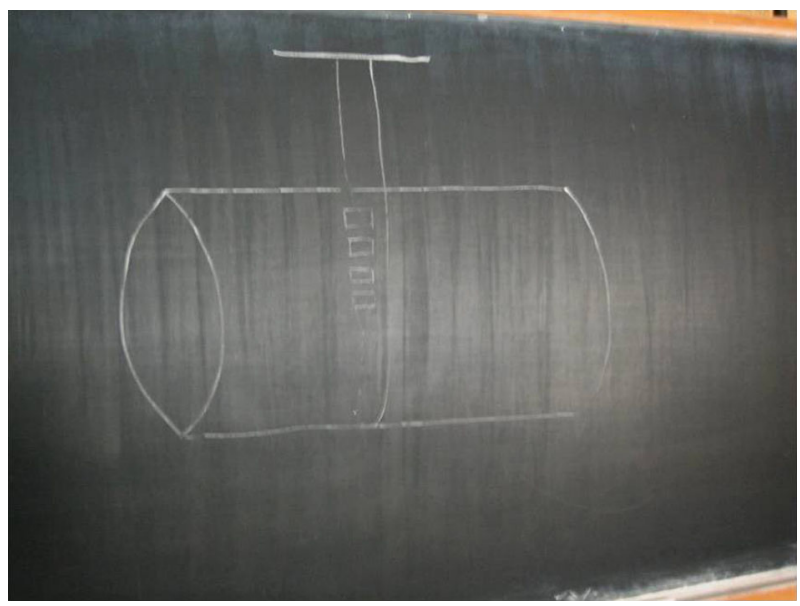

Fig. 9 Schematic diagram of Weber's antenna

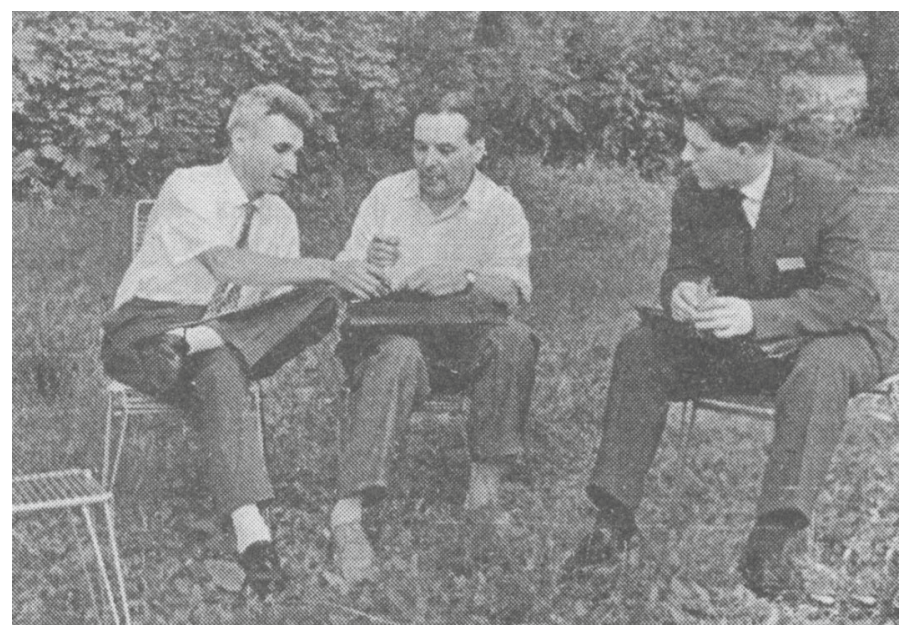

Fig. 10 Dmitri Ivanenko (center) and Yurij Vladimirov (right) talking with Joseph Weber at Jablonna

Jablonna is a small town. There is the nice Palace but really nothing more. The younger and more adventurous participants of the conference were desperately looking for some kind of entertainment. I do not remember who suggested that but they ended up playing hopscotch. I am sure that now you will find more entertainment in Warsaw (Fig. 11).

After the conference I was asked by Professor Infeld to accompany the Diracs (Paul and Margit) to Gdansk. They came by plane but were supposed to take a ship on their way back home. Rooms at a luxurious Grand Hotel in Sopot were reserved and I was sent there to help the Diracs to board the ship next morning. A special car was provided by the Ministry of Higher Education. When we reached Sopot it turned out that the ship had not yet arrived and we had to wait for at least two days. So I had the Diracs for two 


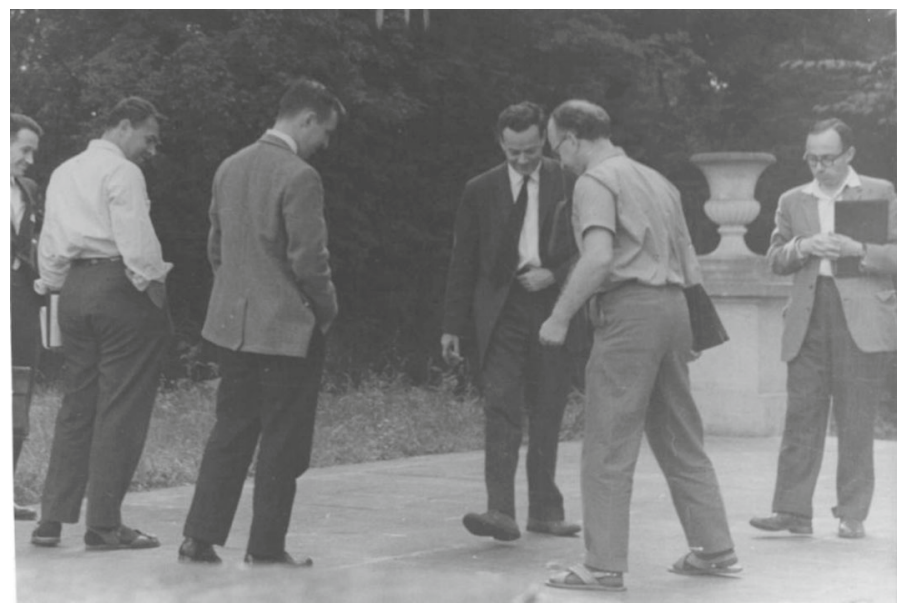

Fig. 11 Richard Feynman and Ivor Robinson playing hopscotch at Jablonna, and from the left Iwo Bialynicki-Birula, Stanley Deser, Charles Misner and Stanley Mandelstam watching

Fig. 12 Paul Dirac with his wife Magrit

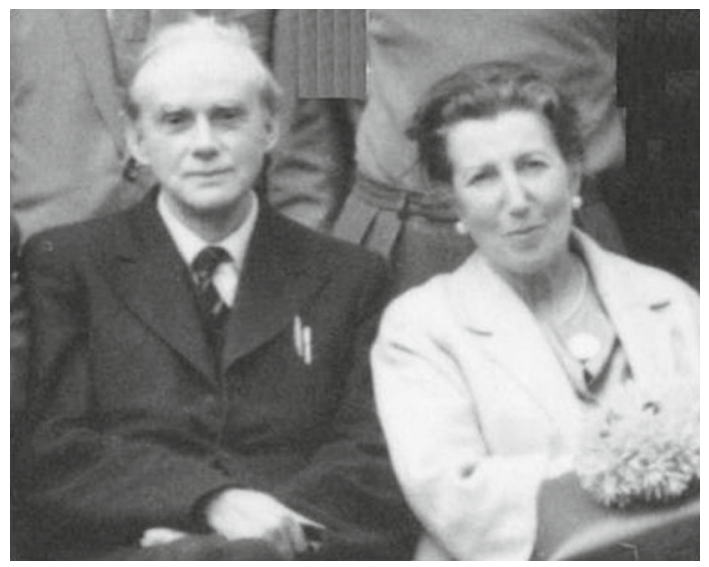

days for myself, plus a car and a chauffeur! During these two days Dirac exchanged with me only handful of words; fortunately his wife Margit was really talkative. She was Hungarian and a sister of Eugene Wigner. We explored Sopot, Gdansk and nearby resort towns. I remember that on our first day in Sopot Margit spotted a farmer's market and we all went there to explore it. It was early August and the market was well stuffed with different kinds of vegetables. Dirac spotted a stack of turnip and we got a few. Can you imagine what kind of sensation we created when after returning to the Grand Hotel I asked a waiter for three plates and a kitchen knife and we set at a patio eating raw turnip that Dirac has meticulously peeled off. Dirac then told me that he likes gardening and that he grows his own vegetables. Just for this it was worth to go to Sopot. But that is not the end of my story (Fig. 12).

Finally I got a message that the ship arrived and next morning I should bring the Diracs to the port. We had a long dinner that day; we discussed the schedule for the 
next morning and I escorted the Diracs to their room and wished them good night. I checked at the hotel reception that everything is arranged for the next morning and went to my room. When I started to undress I heard a knock at my door. I quickly partially dressed up and opened the door. It was Dirac with his rain coat on, he asked me: would you mind to go for a walk. I quickly dressed up and we went to the beach and started to walk along the sea. After a while I became nervous, walking on a beach after sun set was not allowed at that time in Poland as a beach was considered a border zone. Dirac must have noticed that and after a short while he said would you mind to sit down, he spread his rain coat on the damp sand and we sat down. Dirac was silent while we walked. After a while he turned to me and started to ask me who I was, what I was doing, what I was interested in, what I was studying etc. When I told him that I just received my Master degree in physics, he said: you might be interested in my view of physics and started a long monologue. Unfortunately, when we returned back to the hotel, I had to go to sleep as soon as possible since I had to get up very early the next morning. Now I regret that I had not written up all I heard immediately. Fortunately I do remember some important parts. Dirac told me that the most important problem, by the way a problem that has not been solved yet, was to find a quantum theory of gravity. Actually Dirac was thinking about a way of merging theory of gravity with quantum theory, he stressed the word merging. He believed that the key to formulation of the quantum theory of gravity was hidden in the internal structure of elementary particles. He told me that elementary particle physicists treated elementary particles as point objects but this was absurd from the point of view of general relativity. According to Dirac one should try to build even a very simplified model of an extended elementary particle, he was thinking of membranes, shells etc. He said that he could not stop thinking about this problem and that he was very frustrated by the lack of progress. Fifty one years later we are starting the twentieth conference on general relativity and the tenth conference on gravitational waves. With so many bright young minds in the audience to tackle this problem there is hope at last. I wish you the best of luck and make this conference the best you ever attended.

Acknowledgments Figures 2, 6 and 7 were taken at Jablonna by Marek Holzman and Figs. 8, 9, 10 and 11 by Yurij Vladimirov. Figures 4 and 5 were kindly provided by Eryk Infeld.

Open Access This article is distributed under the terms of the Creative Commons Attribution License which permits any use, distribution, and reproduction in any medium, provided the original author(s) and the source are credited. 